\title{
A 39-year-old man with recurrent rheumatic fever
}

\author{
Elizabeth Marie Bagnall BSc, Meghan Jessica Ho BSc MD, lain Alexander McCormick BAH MD
}

See also research article on page 23 and at www.cmaj.ca/lookup/doi/10.1503/cmaj.140772 and commentary on page 13 and at www.cmaj.ca /lookup/doi/10.1503/cmaj.141532

Competing interests: None declared.

This article has been peer reviewed.

The authors have obtained patient consent.

Correspondence to: Meghan Ho, meghan.ho @alum.utoronto.ca

CMAJ 2015. DOI:10.1503 /cmaj.140155
A 39-year-old Filipino man with a history of rheumatic heart disease presented to the emergency department with a three-day history of fever, muscle and joint pain, and headache. The patient's symptoms began one week after he returned from a threeweek trip to the Philippines during which he was well. He reported no infectious exposures and no new sexual contacts.

His medical history was notable for an episode of rheumatic fever that resulted in mitral stenosis. He first received the diagnosis at the age of 28 , when he presented with symptoms of acute rheumatic fever, and echocardiography showed evidence of previous rheumatic damage to the mitral and aortic valves. At the time, it was presumed that this was a recurrence of a disease he likely first contracted after an episode of untreated pharyngitis in the Philippines as a child.

In addition, the patient's medical history included atrial fibrillation, type 2 diabetes mellitus, hypertension and hypercholesterolemia. $\mathrm{He}$ had been taking prophylaxis for rheumatic fever since his initial diagnosis (intramuscular injection of penicillin every $4 \mathrm{wk}, 1200000 \mathrm{U}$ ), in addition to warfarin, bisoprolol, atorvastatin, ramipril, gliclazide, metformin and sitagliptin.

On physical examination, the patient was febrile $\left(38.5^{\circ} \mathrm{C}\right)$, but his vital signs were otherwise normal. Upon cardiovascular examination, he was found to have an opening snap and a middiastolic rumble. His oropharynx was normal. He had no lymphadenopathy, subcutaneous nodules, rash, neck stiffness or peripheral manifestations of endocarditis. No abnormalities were noted in the neurologic and musculoskeletal examinations.

Our initial differential diagnosis was broad because of the nonspecific nature of the symptoms. We considered infectious causes of both fever and arthralgias or arthritis, such as gonococcal infection, Lyme disease and endocarditis, as well as inflammatory causes, such as recurrent rheumatic fever, reactive arthritis and Still disease. In addition, we considered causes of fever in a returning traveller from southeastern Asia (e.g., malaria, dengue, typhoid fever, paratyphoid, hepatitis, respiratory viruses and sexually transmitted infections).

Upon laboratory testing, bacterial cultures of the patient's throat, nasopharynx, urine and blood showed no growth. Results of tests for HIV, hepatitis (A, B and C), gonorrhea, chlamydia, Epstein-Barr virus, cytomegalovirus and dengue were all negative, and blood smear screening for malaria was normal. Laboratory investigations included an antistreptolysin $\mathrm{O}$ titre (251 units; result $>116$ units suggests recent group A streptococcal infection) and C-reactive protein level $(151[$ normal $\leq 4] \mathrm{ng} / \mathrm{mL})$. An electrocardiogram (ECG) showed sinus rhythm with PR prolongation that was unchanged from previous ECGs. A radiograph of the chest was unremarkable. Transesophageal echocardiography showed a rheumatic mitral valve with moderate stenosis and mild regurgitation, a rheumatic regurgitant aortic valve and normal left ventricular size and function.

The clinical evaluation was sufficient to fulfill criteria for recurrent rheumatic fever, 
and the patient was started on amoxicillin (10-d course) and high-dose acetylsalicylic acid (ASA; $1.3 \mathrm{~g}$ by mouth, 4 times daily). Early in the patient's stay in hospital, a right knee effusion and transient $(<24 \mathrm{~h})$ maculopapular erythematous rash on the medial aspect of both knees developed. The symptoms resolved with continued treatment, and the patient was discharged from hospital one week after admission, still taking ASA, with complete resolution of all musculoskeletal, cardiovascular and febrile symptoms.

One week after discharge ( 2.5 wk after his first presentation), the patient returned to hospital with signs and symptoms of congestive heart failure, rate-controlled atrial fibrillation and recurrent myalgias and arthralgias. His second antistreptolysin $\mathrm{O}$ titre was further elevated (539 units). Because his symptoms did not resolve after restarting high-dose ASA therapy, the patient was started on a course of prednisone with a nine-week tapering regimen $(60 \mathrm{mg} / \mathrm{d}$ tapered to 50, 40, 30, 20, 10, 5, 2.5 and $1 \mathrm{mg} / \mathrm{d}$ each week) overlapped with high-dose ASA ( $1.3 \mathrm{~g}$ by mouth 4 times daily) for two weeks. The patient's condition rapidly improved after starting prednisone, and he was discharged from hospital shortly thereafter.

Ongoing management includes secondary prophylaxis with penicillin injection at an increased frequency of once every three weeks. The patient's wife and child were referred to their family physician for screening (group A streptococcal swabs) and treatment if necessary. At his last follow-up appointment nine months after discharge, the patient remained healthy with no recurrence of his symptoms.

\section{Discussion}

Rheumatic fever is a delayed autoimmune response following group A streptococcal infection of the pharynx, which may progress to carditis and lifelong rheumatic heart disease. ${ }^{1,2}$ The disease usually responds favourably to medical management if started early, making prompt diagnosis and treatment crucial. ${ }^{3}$

The development of rheumatic fever after a group A streptococcal infection can have devastating consequences. Rheumatic fever develops as a result of molecular mimicry, whereby structural similarities between streptococcal antigens and human proteins elicit an unwanted adaptive immune response against human cells, notably valvular interstitial cells. ${ }^{1,2}$ Much of the pathogenesis of the disease remains unknown and is an active topic of research. ${ }^{1,2}$

Globally, about 3\% of people with untreated group A streptococcal infections will have rheumatic fever, $30 \%-45 \%$ of whom will go on to have carditis leading to chronic rheumatic heart disease. ${ }^{1,2}$ Thus, antibiotic treatment of streptococcal pharyngitis is important. After the first occurrence, a host is at higher lifelong risk for recurrent rheumatic fever. Secondary prophylaxis with penicillin is recommended by many expert groups. ${ }^{1,3}$

Rheumatic fever has a worldwide incidence of 15 million and 233000 deaths each year. ${ }^{4}$ Disease distribution shows the highest incidences in Pacific and Indigenous Australia and New Zealand (374 cases per 100 000), followed by South Central Asia (54 per 100 000), China (21.2 per 100 000) and other parts of Asia (21.2 per 100 000). ${ }^{4}$ Even though Canadian population studies show a lower incidence of rheumatic fever and rheumatic heart disease than in developing nations, analysis of immigration patterns and population clusters suggest that it will remain an illness of importance in Canada. ${ }^{4,5,6}$

The current prevalence of acute rheumatic fever in Canada is between 0.1 and 2 cases per $100000 .^{4}$ This number could well be increasing — similar populations, such as those of the intermountain region of the United States, have shown recent resurgences of rheumatic fever. ${ }^{5}$ In addition, a shift in Canadian immigration patterns shows increasing numbers of people arriving from countries with endemic rheumatic fever. Asia was the largest source of immigrants from 2006 to 2011, accounting for roughly $56.9 \%$ of immigrants, a considerable shift from 1970, when $78.3 \%$ of immigrants were of European descent. ${ }^{6}$ The Philippines (13.1\%), China $(10.5 \%)$ and India $(10.4 \%)$ represented leading countries of birth for Canadian immigrants from 2006 to 2011, all of which are ranked among the highest for burden of disease of rheumatic fever worldwide. ${ }^{6}$ Finally, new reports have identified clusters of acute rheumatic fever in remote Canadian Aboriginal populations in Northern Ontario with incidences much higher than the national average ( 8.33 per 100000$){ }^{7}$

\section{Diagnosis}

The first set of clinical guidelines for rheumatic fever was the Jones criteria published in 1944, which identified several major and minor criteria for the diagnosis of the disease. ${ }^{8,9}$ These criteria have been reviewed and modified on several occasions, with a comprehensive revision provided in 2003 by the World Health Organization (WHO). ${ }^{1,9}$ The WHO guidelines supplement the original Jones criteria by adding an approach to recurrent episodes of rheumatic fever with and without a history of rheumatic heart disease (Box 1). ${ }^{1}$ 
On initial presentation, our patient underwent evaluation for recurrent rheumatic fever with established rheumatic heart disease. He was found to have three minor criteria (fever, arthralgias and elevated C-reactive protein), with evidence of a recent group A streptococcal infection (elevated antistreptolysin $\mathrm{O}$ titre). These findings were sufficient to fulfill the WHO criteria for a diagnosis of recurrent rheumatic fever (Box 1) and to justify starting treatment immediately. ${ }^{1}$ Early in his hospital stay, the patient showed major manifestations of the condition, such as arthritis and a rash indicative of erythema marginatum. This progression made his presentation all the more convincing for rheumatic fever for which, in accordance with guidelines, he was already receiving treatment.
Cardiac inflammation in rheumatic fever

Establishing the presence of carditis is the most important prognostic factor for both the immediate and long-term progression of rheumatic fever and may guide therapeutic decision-making. ${ }^{1}$ However, as illustrated by our patient's case, clinical identification of active carditis is not always straightforward, particularly in circumstances where heart valves have been previously damaged. Active carditis in acute rheumatic fever is diagnosed by evidence of mitral or aortic regurgitation, pericardial rub or unexplained cardiomegaly with congestive heart failure. ${ }^{1}$ In recurrent rheumatic fever, diagnosis requires showing a change in an existing murmur or progressive valvular damage. ${ }^{1}$ At our patient's first presentation, we were unable to identify recent changes to his diastolic murmur, a radiograph of his chest or

Box 1: World Health Organization revised Jones criteria for the diagnosis of rheumatic fever ${ }^{1}$

\begin{tabular}{|c|c|}
\hline Diagnostic categories & Criteria \\
\hline Primary episode of rheumatic fever* & $\begin{array}{l}\text { Two major or } 1 \text { major and } 2 \text { minor manifestations plus evidence of } \\
\text { a preceding group A streptococcal infection }\end{array}$ \\
\hline $\begin{array}{l}\text { Recurrent episode of rheumatic fever in a patient without } \\
\text { established rheumatic heart disease } t\end{array}$ & $\begin{array}{l}\text { Two major or } 1 \text { major and } 2 \text { minor manifestations plus evidence of } \\
\text { a preceding group A streptococcal infection }\end{array}$ \\
\hline $\begin{array}{l}\text { Recurrent episode of rheumatic fever in a patient with } \\
\text { established rheumatic heart disease }\end{array}$ & $\begin{array}{l}\text { Two minor manifestations plus evidence of a preceding group A } \\
\text { streptococcal infection } \neq\end{array}$ \\
\hline Rheumatic chorea & $\begin{array}{l}\text { Other manifestations or evidence of group A streptococcal } \\
\text { infection not required }\end{array}$ \\
\hline $\begin{array}{l}\text { Chronic valve lesions of rheumatic heart disease (patients } \\
\text { presenting for the first time with pure mitral stenosis or } \\
\text { mixed mitral valve disease and aortic valve disease)§ }\end{array}$ & No other criteria required for diagnosis of rheumatic heart disease \\
\hline Major manifestations & $\begin{array}{l}\text { - } \text { carditis } \\
\text { - polyarthritis } \\
\text { - chorea } \\
\text { - erythema marginatum } \\
\text { - subcutaneous nodules }\end{array}$ \\
\hline Minor manifestations & $\begin{array}{l}\text { - fever } \\
\text { - polyarthralgia } \\
\text { - elevated acute phase reactants (erythrocyte sedimentation rate } \\
\text { or leukocyte count) }\end{array}$ \\
\hline $\begin{array}{l}\text { Supporting evidence of a preceding streptococcal infection } \\
\text { within the last } 45 d\end{array}$ & $\begin{array}{l}\text { - electrocardiogram (prolonged P-R interval) } \\
\text { - elevated or rising antistreptolysin O or other streptococcal } \\
\text { antibody titre, or } \\
\text { - a positive throat culture, or } \\
\text { - a rapid antigen test for group A streptococci or recent scarlet } \\
\text { fever }\end{array}$ \\
\hline \multicolumn{2}{|c|}{$\begin{array}{l}\text { *Patients may present with polyarthritis (or with only polyarthralgia or monoarthritis) and with several ( } 3 \text { or more) other minor manifestations, together with } \\
\text { evidence of recent group A streptococcal infection. Some of these cases may later turn out to be rheumatic fever. It is prudent to consider them as cases of } \\
\text { "probable rheumatic fever" (once other diagnoses are excluded) and advise regular secondary prophylaxis. Such patients require close follow up and regular } \\
\text { examination of the heart. This cautious approach is particularly suitable for patients in vulnerable age groups in high incidence settings. } \\
\text { tInfective endocarditis should be excluded. } \\
\text { tSome patients with recurrent attacks may not fulfill these criteria. } \\
\text { \$Congenital heart disease should be excluded. } \\
\text { Reproduced with permission from Rheumatic fever and rheumatic heart disease: report of a WHO expert consultation, Geneva, 29 October-1 November } 2001 \text {. } \\
\text { No. } 923 \text { of WHO Technical Report Series. Geneva: World Health Organization; 2001, available http://whqlibdoc.who.int/trs/WHO_TRS_923.pdf?ua=1 (accessed 2013 } \\
\text { Nov. 20). }\end{array}$} \\
\hline
\end{tabular}


ECG. Transthoracic echocardiography showed progression from mild to moderate mitral stenosis without changes to mitral or aortic regurgitation. Evidence to confirm active carditis early on was insufficient. However, when the patient returned to hospital with signs and symptoms of congestive heart failure, his symptoms were increasingly suspicious for cardiac inflammation, and corticosteroid treatment was started accordingly. His rapid response to treatment was further evidence of likely cardiac inflammation. This case shows that establishing carditis in recurrent rheumatic fever is often difficult, but it may prove important in the management of the disease.

\section{Management}

The first-line treatment for rheumatic fever is penicillin $\mathrm{V}$ with an anti-inflammatory therapy such as ASA or corticosteroids. A course of $500 \mathrm{mg}$ of penicillin $\mathrm{V}$ two to three times per day for 10 days is the recommended antibiotic therapy for adults. ${ }^{3}$ A 10-day course of either amoxicillin or cephalosporins taken orally are adequate alternatives. ${ }^{3}$

Although anti-inflammatory therapy is recommended for cases with cardiac inflammation, the choice of anti-inflammatory agent remains controversial because of poor evidence of longterm efficacy and substantial adverse effects. ${ }^{5}$ The two main choices for anti-inflammatory therapy are high-dose ASA $(100 \mathrm{mg} / \mathrm{kg}$ per day or higher as needed) or prednisone $(2 \mathrm{mg} / \mathrm{kg}$ per day, $80 \mathrm{mg} / \mathrm{d}$ maximum) for a duration based on clinical response, normalization of acute phase reactants and tolerability. ${ }^{1}$ A recent Cochrane meta-analysis of salicylates and steroids showed no significant improvement in cardiac outcomes one year after either treatment, although both treatments improved clinical response in the short-term. $^{5}$

Tolerability may also affect treatment decisionmaking. Adverse effects with steroids include weight gain, altered fat distribution, acne and gastric ulcers. Caution should be used when giving steroids to patients with pre-existing cardiovascular, gastrointestinal, diabetic or osteoporotic disease. ${ }^{5}$ Adverse effects from high-dose ASA include tinnitus, deafness, nausea and hyperventilation. ${ }^{5}$ Despite mixed evidence, the recommendation of expert groups has been to give salicylates to patients with mild or moderate carditis and to use corticosteroids for severe carditis, pancarditis, heart failure or poor response to salicylates. ${ }^{1,5}$

Our patient first presented without evidence of severe carditis and was given amoxicillin and ASA. Dosing of ASA was limited to lower than the recommended dose $(\sim 70 \mathrm{mg} / \mathrm{kg}$ per day $)$ because he had an elevated international normalized ratio with warfarin treatment. When the patient returned to hospital with signs of severe carditis, we started prednisone therapy $(60 \mathrm{mg} / \mathrm{d})$ tapered over nine weeks according to clinical response, with an overlap with ASA to avoid rebound. ${ }^{1}$ The patient responded well to treatment.

\section{Secondary prophylaxis and household contacts}

The two main issues remaining after successful management of rheumatic fever are secondary prophylaxis and management of household contacts.

For prophylaxis, injectable penicillin is recommended over oral, as compliance is higher. ${ }^{1}$ The duration of prophylaxis is determined by risk of recurrence, ranging from five years to lifelong $^{1}$ (Box 2). The recommended frequency of penicillin injection is every three or four weeks based on patient risk factors (i.e., age, socioeconomic status, crowded living quarters, risk of group A streptococcus in area of residence, risk of employment exposure), as well as disease history (e.g., chronic valvular disease, number of recurrent attacks, time since previous occurrence, family history of rheumatic fever). ${ }^{1}$ If a four-week program is chosen, serum drug levels may fall below the protective level before the fourth week, which may explain our patient's recurrence of rheumatic fever while receiving prophylactic treatment. ${ }^{3}$ In light of his recurrence, chronic valvular damage and high-risk stratification, our patient was changed to a threeweek program of prophylaxis for his lifetime.

In Canada, rheumatic fever is not reportable, and there are no Canadian guidelines outlining its treatment in close contacts. ${ }^{7}$ Many expert committees, including the American Heart Association, give a strong recommendation for routine screening of household contacts..$^{3,10}$ Guidelines from New Zealand give the most comprehensive description of screening. ${ }^{10}$ These

Box 2: Suggested duration of secondary prophylaxis (benzathine benzylpenicillin) after an occurrence of rheumatic fever ${ }^{1}$

Category of patient

Duration of prophylaxis

Patient without proven carditis For $5 \mathrm{yr}$ after the last attack, or until age $18 \mathrm{yr}$ (whichever is longer)

Patient with carditis (mild mitral For $10 \mathrm{yr}$ after the last attack, or at least regurgitation or healed carditis) until age $25 \mathrm{yr}$ (whichever is longer)

More severe valvular disease Lifelong

After valve surgery Lifelong

*These are recommendations and must be modified by individual circumstances as warranted Reproduced with permission from Rheumatic fever and rheumatic heart disease: report of a WHO expert consultation, Geneva, 29 October - 1 November 2001. no. 923 of WHO Technical Report Series. Geneva: World Health Organization; 2001, available http://whqlibdoc.who.int/ trs/WHO_TRS_923.pdf (accessed 2013 Nov. 20). 
guidelines recommend screening for all close contacts, defined as people in proximity to the patient up to one month before the onset of the illness. Contacts undergo screening with a throat swab for group A streptococcus, and those with positive results promptly receive treatment with penicillin $\mathrm{V}$ for 10 days. In our patient's case, his close contacts were referred to their family physician for screening. Although the role of the physician is to offer treatment and explain its necessity, compliance is not enforced in Canada and remains the patient's choice.

\section{References}

1. Rheumatic fever and rheumatic heart disease: report of a WHO expert consultation, Geneva, 29 October - 1 November 2001. no. 923 of WHO Technical Report Series. Geneva: World Health Organization; 2001. Available: http://whqlibdoc.who.int/trs /WHO_TRS_923.pdf (accessed 2013 Nov. 20).

2. Guilherme L, Kalil J. Rheumatic fever and rheumatic heart disease: cellular mechanisms leading to autoimmune reactivity and disease. J Clin Immunol 2010;30:17-23.

3. Gerber MA, Baltimore RS, Eaton CB, et al. Prevention of rheumatic fever and diagnosis and treatment of acute streptococcal pharyngitis: a scientific statement from the American Heart Association rheumatic fever, endocarditis and Kawasaki disease committee of the council on cardiovascular disease in the young, the Interdisciplinary council on functional genomics and translational biology and the interdisciplinary council on quality of care and outcomes research: endorsed by the American Academy of Pediatrics. Circulation 2009;119:1541-51.

4. Carapetis JR, Steer A, Mulholland E, et al. The global burden of group A streptococcal diseases. Lancet Infect Dis 2005;5:685-94.

5. Cilliers A, Manyemba J, Adler AJ, et al. Anti-inflammatory treatment for carditis in acute rheumatic fever. Cochrane Database Syst Rev 2012;6:CD003176.

6. Immigration and ethnocultural diversity in Canada. Ottawa: Statistics Canada; 2011. Available: www12.statcan.gc.ca/nhs -enm/2011/as-sa/99-010-x/99-010-x2011001-eng.cfm (accessed 2014 Apr. 20).

7. Madden S, Kelly L. Update on acute rheumatic fever: it still exists in remote communities. Can Fam Physician 2009;55:475-8.

8. Jones TD. Diagnosis of rheumatic fever. JAMA 1944;126:481-4.

9. Guidelines for the diagnosis of rheumatic fever: Jones criteria 1992 update. Special writing group of the committee on rheumatic fever, endocarditis and Kawasaki disease of the council of cardiovascular disease in the young of the American Heart Association. JAMA 1992;268:2069-73 Available: www.rhdaustralia.org.au/sites/default/files /guideline 0.pdf (accessed 2013 Dec. 10).

10. Communicable disease control manual: rheumatic fever. New Zealand: Ministry of Health; 2012. Available: www.health.govt nz/system/files/documents/publications/cd-manual-rheumatic -fever-may2012.pdf (accessed 2014 Apr. 23).

Affiliation: Department of Medicine, University of British Columbia, Vancouver, BC

Contributors: Meghan Ho and Iain McCormick were involved in the patient's care. Meghan Ho acquired patient permission and, with Iain McCormick, conceived the idea for the report. Elizabeth Bagnall took the lead role in drafting the manuscript, with assistance from Meghan Ho. All authors contributed to the discussion content and several revised versions of the manuscript. All authors gave final approval of the manuscript and agree to act as guarantors.

Acknowledgements: The authors thank the patient for allowing us to share his case; Dr. Nasim Mahmoudi, Dr. Kiran Sidhu, Dr. Anna Dabu, the clinical teaching unit care team and the Infectious Disease and Rheumatology Services for their clinical expertise and guidance; Cecilia Nishi for her pharmacological advice; and the World Health Organization for granting permission to reproduce their tables in this report.

The section Cases presents brief case reports that convey clear, practical lessons. Preference is given to common presentations of important rare conditions, and important unusual presentations of common problems. Articles start with a case presentation (500 words maximum), and a discussion of the underlying condition follows (1000 words maximum). Visual elements (e.g., tables of the differential diagnosis, clinical features or diagnostic approach) are encouraged. Written consent from patients for publication of their story is a necessity and should accompany submissions. See information for authors at www.cmaj.ca.

\section{Changement d'adresse}

II nous faut de 6 à 8 semaines d'avis afin de vous assurer une livraison ininterrompue. Veuillez faire parvenir votre étiquette d'adresse actuelle, votre nouvelle adresse et la date de la prise d'effet du changement, à l'attention du

Centre des services aux membres de l'AMC 1870, prom. Alta Vista, Ottawa ON K1G 6R7

tél 888 855-2555 ou $613731-8610$ x2307 fax 613 236-8864 cmamsc@cma.ca

\section{Change of address}

We require 6 to 8 weeks' notice to ensure uninterrupted service. Please send your current mailing label, new address and the effective date of change to:

\section{CMA Member Service Centre} 1870 Alta Vista Dr., Ottawa ON K1G 6R7

tel $888855-2555$ or $613731-8610 \times 2307$

fax 613 236-8864

cmamsc@cma.ca

\section{ASSOCIATION \\ MÉDICALE CANADIENNE \\ CANADIAN \\ MEDICAL \\ Association}

